\title{
On the Disadvantages of the NEHRP Soil Classification
}

\author{
Alexander Stepanovich Aleshin \\ Institute of Physics of the Earth, Russian Academy of Sciences, Moscow, Russia \\ Email: asa@ifz.ru
}

How to cite this paper: Aleshin, A.S. (2021) On the Disadvantages of the NEHRP Soil Classification. Open Journal of Earthquake Research, 10, 1-15. https://doi.org/10.4236/ojer.2021.101001

Received: January 8, 2021

Accepted: February 23, 2021

Published: February 26, 2021

Copyright $\odot 2021$ by author(s) and Scientific Research Publishing Inc. This work is licensed under the Creative Commons Attribution International License (CC BY 4.0).

http://creativecommons.org/licenses/by/4.0/ (c) (i) Open Access

\begin{abstract}
The study of the relationship of local ground conditions with the parameters of seismic vibrations carried out by the section of engineering seismology called seismic microzonation. In this branch of applied science radical changes have taken place at the end of the last century. The Commission on Seismic Safety of the National Institute of Building Sciences of the United States has developed new recommendations, which are significantly different from all that used in the world practice of anti-seismic construction. The main provisions of this NEHRP (National Earthquake Hazards Reduction Program) classification adopted in many national building codes, including Eurocode 8. At the same time, a number of papers appeared in subsequent years criticizing the use of the NEHRP soil classification. This article examines in detail and, most importantly, comprehensively the shortcomings of the NEHRP classification.
\end{abstract}

\section{Keywords}

Seismic Site Properties Classification, Site Class

\section{Introduction}

The study of the relationship of local ground conditions with the parameters of seismic vibrations carried out by the section of engineering seismology called seismic microzonation. In this branch of applied science radical changes have taken place at the end of the last century. The Commission on Seismic Safety of the National Institute of Building Sciences of the United States has developed new recommendations [1], which are significantly different from all that used in the world practice of anti-seismic construction. The main provisions of this NEHRP (National Earthquake Hazards Reduction Program) classification adopt in many national building codes, including Eurocode 8 [2]. 
Despite the undoubted advantages [3], in a number of works [4] [5] [6] [7] [8] it was noted that the classification of soils, determined by the requirements of the Recommendations [1], leads to an erroneous assessment of the levels of soil reinforcement and, as a result, to incorrect estimates of seismic hazard. The researchers mainly paid attention to the discrepancy between the soil conditions in different regions of the world (for example, in India, China, Australia, Israel, Greece, Italy) and the soil conditions of the United States.

It is obvious that at the position of the rocky ground above $30 \mathrm{~m}$, the value of the average velocity in the $30 \mathrm{~m}$ layer increases and there is a fictitious increase in the rigidity of the upper soil layer, leading to a decrease in the calculated value of the intensity increment or decrease site coefficient $F_{a}$. This situation was in contradiction with the established practice of seismic engineering surveys.

At the position of the roof of the rock half-space at depth $H$ and at the shear wave velocity in the loose layer $V_{1}$ and in the rock half-space $V_{0}$, the average velocity of the upper 30-meter layer is determined by the expression: $\langle V(H)\rangle=$ $30 /\left((30-H) / V_{0}+\left(H / V_{1}\right)\right)$. Substituting in this expression $H<30 \mathrm{~m}, V_{1}=300$ $\mathrm{m} / \mathrm{s}, V_{0}=800 \mathrm{~m} / \mathrm{s}$, getting the values of average values of shear wave velocity $\langle\mathrm{V}\rangle$, which differs both from the values in the lower half-space and from the values of the velocity in the layer of loose soil.

Of particular importance are these observations due to the fact that in many cases researchers use the method of studying the upper part of the soil using the ratio of the amplitudes of the horizontal and vertical components of microseismic vibrations, also known as the Nakamura method, in which the parameters of the soil massif are determined with some averaging.

In Russian surveys, much more attention is paid to the direct study of soils using engineering and geological data obtained during the drilling of exploration wells, which allows determine the position of the roof of the rock half-space more accurately and take into account the effect of a fictitious increase in soil rigidity. The noted lack of NEHRP recommendations eliminate in modern Russian norms [9], where the estimated thickness of the soil is determined by the thickness up to the boundary with increased seismic rigidity, if it is present in the upper 30meter thickness of the soil cross-section.

It should be noted that the most important feature of an adequate soil classification is the requirement of mutual compliance, i.e. the necessity and sufficiency to put one set of soil parameters in accordance with one and only one set of parameters of seismic impacts.

The purpose of this study is to check whether the NEHRP classification meets the specified requirements. There are several possible reasons for this discrepancy. Consider them sequentially.

\section{Research Methodology}

Verification of the validity of the classification of NEHRP consists in comparing the parameters of the soil to seismic impacts using a series of model examples. 
According to the classification of NEHRP, the site class is determined mainly by the value of the velocity of shear waves in the 30-meters layer of soil lying on the roof of a rigid elastic half-space. The corresponding seismic impacts are determined by the site coefficients. In the book [10] it is shown that the site coefficients can be obtained as dynamic coefficients in a result of modeling on a series of models of the ground massif corresponding to the site classes from A to E.

To determine the dynamic coefficients, we will use the NERA program. We calculate the response spectra on the models using the NERA program [11]. The oscillations in the model are excited by a short pulse with a duration of one sample and an amplitude of $0.1 \mathrm{~g}$, which ensures the linearity of the processes in the model. As is known [12], the response of a linear system (including a system of soil layers) to a short pulse is a pulse response, the spectrum of which is the frequency characteristic of the system. The advantage of this method of investigation is that in this case there is no need to know and take into account the spectrum of the input (exciting) action-in the spectrum of the input pulse there are "all frequencies". The output data in the NERA program is the Fourier spectrum and the response spectrum. The dynamic coefficient calculates as the response spectrum normalized on the shortest ("zero") period. The values of dynamic coefficients, normalized on a value corresponding to the model of a site category $\mathrm{B}$, give a values close to the gain for the short-period part of the spectrum $F_{a}$, corresponding to the site classes of classification NEHRP, that shown in Table 1.

In the following part of the work, the results of comparing the data obtained during the modeling of various model situations with the data of Table 1 presented. If these two types of data show a satisfactory match, this will mean that the site classification of NEHRP soils corresponds to the real simulated situation.

In the following part of the work, the results of comparing the data obtained during the modeling of various model situations with the data of Table 1 presented. If these two types of data show a satisfactory match, this will mean that the site classification of NEHRP soils corresponds to the real simulated situation.

\section{Results of Research}

The results of the research presented in this article in the form of short paragraphs of the text, provided with appropriate explanatory figures that display various consecutive fragments of the general consideration of the named topic.

Table 1. Sire coefficients of short-period $F_{a}$ of NEHRP classification.

\begin{tabular}{ccc}
\hline Site class & Velocity $V_{s}, \mathrm{~m} / \mathrm{s}$ & Site coefficient $F_{\text {a }}$ for linear part of seismic impacts \\
\hline A & $>1500$ & 0.8 \\
B & $760-1500$ & 1.0 \\
C & $360-760$ & 1.2 \\
D & $180-360$ & 1.6 \\
E & $<180$ & 2.5 \\
\hline
\end{tabular}




\subsection{On the Characteristics of the Soil Layer Properties}

Another aspect of this problem relates to the correct definition of the soil massif seismic properties. In the NEHRP norms, this choice made exclusively in favor of the average shear wave velocity. This choice is certainly correct, since the shear wave velocity more adequately corresponds to the properties of the soil and, in addition, on the shear wave velocity is less effect of water saturation.

Meanwhile, the shear wave velocity, although it is the most important characteristic of the seismic properties of the soil massif, it is not the only value that determines the seismic properties of the soil. The reaction of the soil to seismic impacts also determined by the density, or more accurately seismic rigidity-the product of the density and the shear wave velocity. It is appropriate to note that this value appears as the main quantitative characteristic of soil properties in Russian standards [9] [13]. The argument that the density of soils does not change so significantly relative to changes in velocity is not fundamental importance.

Let us compare the choice of different characteristics of soil properties-the average shear wave velocity or the average seismic rigidity in the upper 30-meter thickness of the soil on specific model examples.

For this purpose we study two models with the same $V_{s}$ velocity value and different density and, accordingly, different seismic rigidity. For comparison, the model of the site class B is also studied. The parameters of the models show in Table 2. According to the NEHRP classification, both models belong to site class D. On the other hand, the seismic rigidity of the loose layer of both models is different.

Figure 1 shows the dynamic coefficients of all models. As follows from Figure 1 , the maxima of the dynamic coefficients are equal to 2.5 for the $1 \mathrm{C}$ model, 2.9 for the $2 \mathrm{D}$ model and 1.85 for the $\mathrm{B}$ model. Therefore, the values of the site coefficients are equal to $2.5 / 1.85=1.35$ for the $1 \mathrm{C}$ model and $2.9 / 1.85=1.57$ for the $2 \mathrm{D}$ model. Thus, although both models on the shear wave velocity values belong to the ground class $\mathrm{D}$, the site coefficients for them differ significantly. Only the 2D model corresponds to the classification of NEHRP. For the model 1C the value of site coefficient is noticeably lower than the standard value.

The results of such a comparison show that the model data obtained contradict the data in Table 1 and the general classification requirements, which imply that if the soils belong to the same soil class, the site coefficients, consequently, the accelerations must be equal. At the same time, the acceleration values for the 2D model with lower seismic rigidity of upper layer exceed the acceleration values for the $1 \mathrm{C}$ model with greater seismic rigidity of the same. Thus, the seismic rigidity as the main parameter that characterizes the properties of the soil better corresponds to the general classification criteria.

Now consider two models of soils with different average shear wave velocities values, but the seismic rigidities of the loose layer of both models is almost the same. Parameters of soil models showed in Table 3. 
Table 2. Parameters of soil models with the same shear .wave velocities.

\begin{tabular}{cccc}
\hline \multicolumn{5}{c}{ Model 1C } \\
\hline Thickness, $\mathrm{m}$ & Density, $\mathrm{t} / \mathrm{m}^{3}$ & Velocity $V_{s,} \mathrm{~m} / \mathrm{s}$ & Seismic rigidity, $\mathrm{t} \cdot \mathrm{m}^{-2} \cdot \mathrm{s}^{-1}$ \\
\hline 30 & 2.2 & 350 & 770 \\
$\infty$ & 2.5 & 800 & 2000 \\
\hline 30 & \multicolumn{3}{c}{ Model 2D } \\
\hline$\infty$ & 1.7 & 350 & 595 \\
\hline 30 & 2.5 & 800 & 2000 \\
\hline$\infty$ & & Model B & 2000 \\
\hline
\end{tabular}

Table 3. Parameters of models with close values of the seismic rigidity of the upper layer.

\begin{tabular}{cccc}
\hline \multicolumn{4}{c}{ Model of site class C } \\
\hline Depth, $\mathrm{m}$ & Density, $\mathrm{t} / \mathrm{m}^{3}$ & Velocity $V_{s}, \mathrm{~m} / \mathrm{c}$ & Seismic rigidity, $\mathbf{t} \cdot \mathrm{m}^{-2} \cdot \mathrm{s}^{-1}$ \\
\hline 30 & 1.8 & 390 & 702 \\
$\infty$ & 2.5 & 800 & 2000 \\
\hline 30 & 2.1 & Model of site class D & 701.4 \\
$\infty$ & 2.5 & 334 & 2000 \\
\hline
\end{tabular}

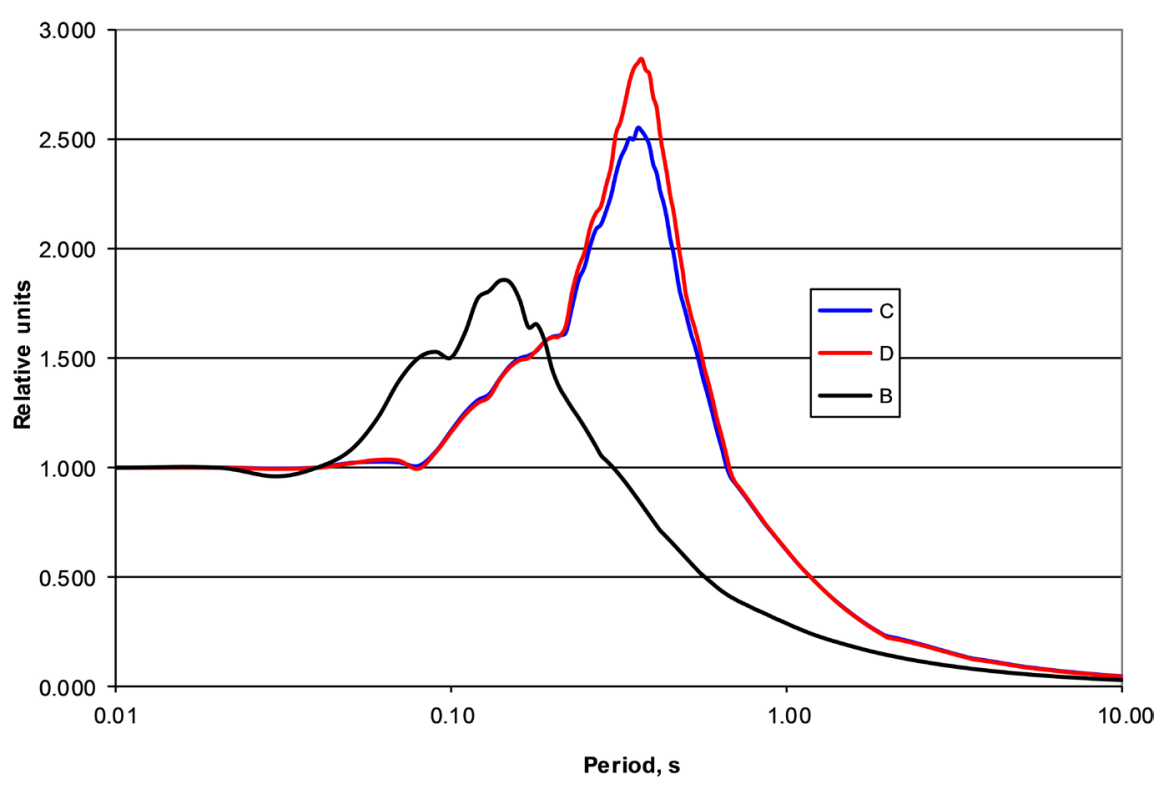

Figure 1. Dynamic coefficients of models 1C, 2D and B.

By the NHRP classification, the first model belongs to the site class $\mathrm{C}$, since $V_{\mathrm{s}, 30}>360 \mathrm{~m} / \mathrm{s}$. The other model belongs to site class $\mathrm{D}$, since $V_{\mathrm{s}, 30}<360 \mathrm{~m} / \mathrm{s}$.

Graphs of the dynamic coefficients of models $\mathrm{C}$ and D shown in Figure 2. It is 


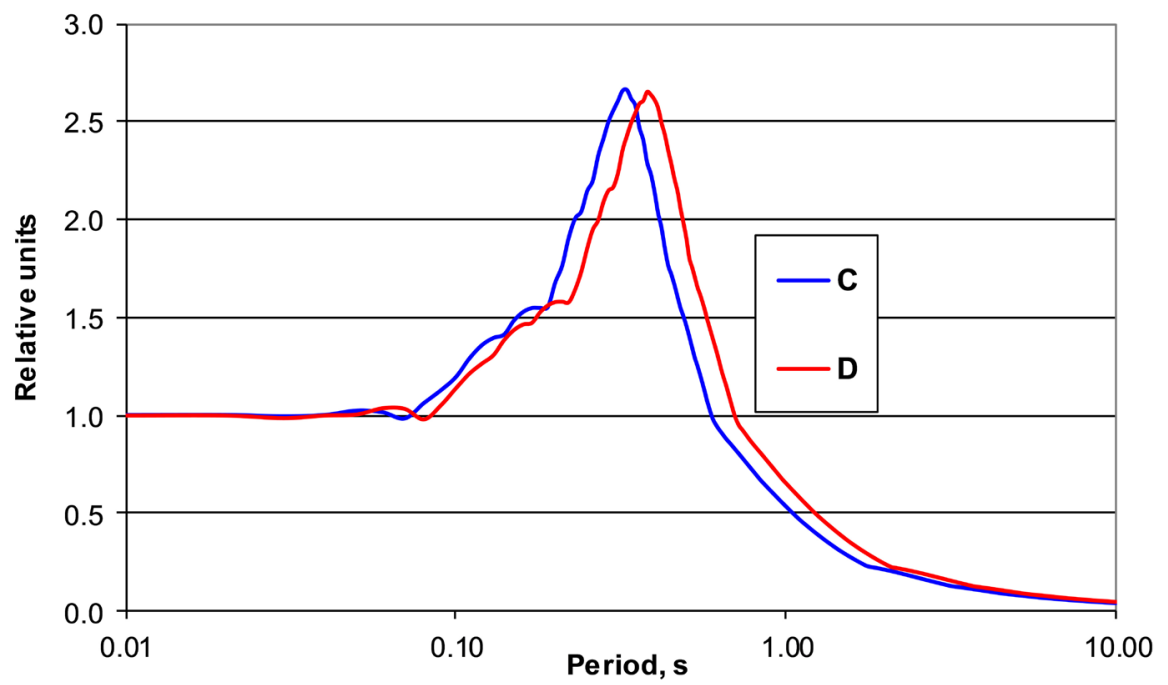

Figure 2. Dynamic coefficients of models $\mathrm{C}$ and $\mathrm{D}$ with close values of the seismic rigidity of the upper layer.

obvious that the values of the maxima of the coefficients practically coincide, which indicates that both models belong to the same soil classes, if the classification is based not on the $V s$ velocity, but on seismic rigidity.

On the other hand, the periods of maxima of the dynamic coefficients correspond to the values of the velocities of the loose layer. Given that the thickness of the loose layer $H=30 \mathrm{~m}$ corresponds to a quarter of the wavelength for site class $\mathrm{C}$, the resonance period (the period of the maximum dynamic coefficient) is noted at the period $T c=120 / 390=0.31 \mathrm{~s}$, and for site class D at the period $T d=$ $120 / 334=0.36 \mathrm{~s}$.

Thus, we find that the use of seismic rigidity as a characteristic of soil properties of upper layer is more adequate than the values of average velocities $V_{\mathrm{S}, 30}$, correspond to the results of modeling and, therefore, should be used as the basis concept for soil classification.

\subsection{The Concept of Continuity}

The use of seismic rigidity as a characteristic of soil properties allows a new approach to determining the nature of the relationship between soil properties and parameters of seismic impacts. To do this, we will also use the results of modeling a family of single-layer models, the parameters of the upper layer of which (shear wave velocities and densities) correspond to the soil classes defined by the NEHRP classification. The seismic rigidity of the underlying rigid half-space is equal to $2200 \mathrm{t} \cdot \mathrm{m}^{-2} \cdot \mathrm{s}^{-1}$. The model parameters show in Table 4.

It is possible to construct a graph of the relationship between the parameters of seismic impacts, represented by site coefficients, and the characteristics of soil properties, presented by the shear wave velocities, in accordance of the NEHRP classification, using the simulation results. This graph showed in Figure 3.

In Figure 3 by a solid curve line showing the continuous dependence of ground 
Table 4. Modeling of site coefficients.

\begin{tabular}{cccccc}
\hline Site class & $\begin{array}{c}\text { Density, } \\
\mathbf{t} / \mathrm{m}^{3}\end{array}$ & $\begin{array}{c}\text { Velocity, } V_{\boldsymbol{s}}, \\
\mathrm{m} / \mathrm{s}\end{array}$ & $\begin{array}{c}\text { Seismic rigidity, } \\
\mathrm{t} \cdot \mathrm{m}^{-2} \cdot \mathbf{s}^{-1}\end{array}$ & $\begin{array}{c}\text { Maximum of } \\
\text { dynamic coefficient } \\
\text { динамичности }\end{array}$ & $\begin{array}{c}\text { Site } \\
\text { сoefficient }\end{array}$ \\
\hline A & 2.4 & 1700 & 4080 & 1.88 & 1 \\
В & 2.2 & 1000 & 2200 & 1.9 & 1 \\
C & 1.9 & 580 & 1100 & 2.34 & 1.23 \\
D & 1.7 & 290 & 493 & 3.28 & 1.7 \\
E & 1.5 & 100 & 150 & 5.32 & 2.8 \\
\hline
\end{tabular}

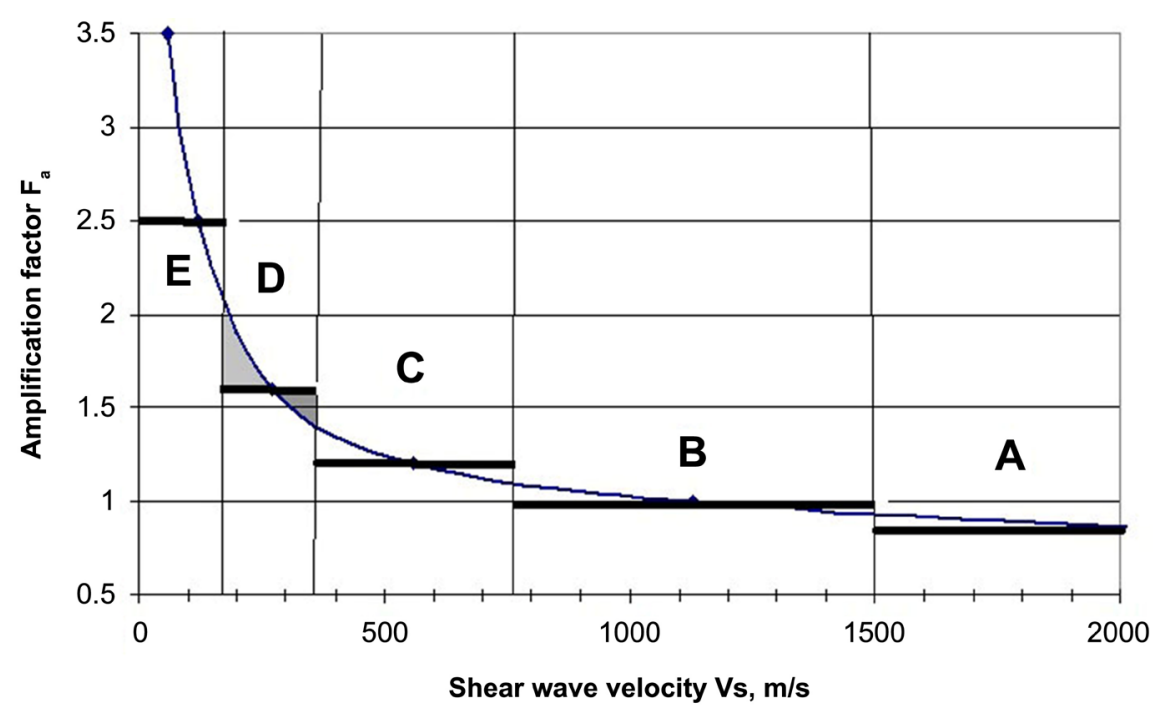

Figure 3. Dependence of site coefficients on the velocity of shear wave in the soil.

coefficients on the shear wave velocity in the soil, bold horizontal lines show the values of site coefficients determined by the NEHRP classification. Thin vertical lines mark the boundaries of soil classes. It is obvious that the constant values of the site coefficients correspond exactly to the values of $V_{s, 30}$ only at one point. In Figure 3, the section of zone $\mathrm{D}$ in which the normative values are less than the real values of soil coefficients highlighted by light gray, and in the section highlighted in more dark color, the normative values exceed the real values of site coefficients. In addition, at the boundaries of the zones, the values of site coefficients undergo discontinuities. These observations show that the approximation of site coefficients by constant values for individual site classes is unsatisfactory. These arguments represent part of the general concept of continuity (spatial continuity), described in more detail in the book [6].

\subsection{The Structure Factor}

So far, all the models characterized by the same parameters: either the average shear velocity to 30-meter upper layer of soil, or seismic rigidity, i.e. the product of average density on the average shear velocity of the same layer of soil. However, there is one circumstance, which not been taken into account. And it is, as 
we shall see, very important. This is the internal structure of a 30-meter layer of soil. When we talk about the internal structure, we mean the order of alternating layers in the array, which can be arbitrary, although the average values of velocities and densities are preserved. For example, consider two simple models that include two layers with increased and reduced values of velocities and densities. The parameters of two-layer models showed in Table 5.

The calculations as usually performed using the NERA program. In this case, we use the response spectrum as the output data, since it displays both the frequency and amplitude features of the oscillations. The obtained results showed for comparison in one Figure 4.

It is obvious that for the $\mathrm{C}+15$ and $\mathrm{C}-15$ models, both the type of spectral curves and, most clearly, the level of spectra differ. The accelerations of the model $\mathrm{C}+15$ are about 1.5 times lower, due to the in the structure of the model $\mathrm{C}+15$ there is an inverse low-speed layer, and the upper part of the section in the model $\mathrm{C}+15$ is a layer with high seismic rigidity. Thus, a seismic wave coming from below a rigid half-space weakened due to two factors. First, at the inverse boundary - the roof of a layer with reduced rigidity-part of the energy thrown back into the lower half-space. Secondly, on the roof of the upper layer, the vibrations will be lower precisely because of the increased (relative to the $\mathrm{C}-$ 15 model) rigidity.

It can assumed that the detected differences in the dynamic coefficients of both models are somehow related to the thickness of alternating layers, and with a decrease in the thickness of a single layer, the "heterogeneity" of the model decreases, which can manifest itself in a decrease of differences in spectral characteristics. That this is the case shows the following model example, in which two models with $1 \mathrm{~m}$ thick layers alternating in seismic rigidity are studied. The models differ in the seismic rigidity of the topmost layer. The total thickness of the "comb" of overlapping layers is $30 \mathrm{~m}$ and it underlain by a half-space with increased seismic rigidity. Figure 5 shows the dynamic coefficients, which, as shown, are exactly the same.

As follows from Figure 5, the maximum dynamic coefficients barely exceed 2 . For comparison, Figure 6 shows a graph of the dynamic coefficient of the average model with the parameters $\langle\rho\rangle=2 \mathrm{t} \cdot \mathrm{m}^{-2} \cdot \mathrm{c}^{-1}\left\langle V_{s}\right\rangle=500 \mathrm{~m} / \mathrm{s}$.

Table 5. Parameters of two-layer models of soil massif.

\begin{tabular}{cccc}
\hline \multicolumn{3}{c}{ Model C $+\mathbf{1 5}$} \\
\hline Number of layer & Density, $\mathbf{t} / \mathbf{m}^{3}$ & Velocity $V_{s}, \mathrm{~m} / \mathbf{s}$ & Layer thickness, $\mathbf{m}$ \\
\hline 1 & 2.0 & 667 & 15 \\
2 & 1.8 & 400 & 15 \\
3 & 2.2 & 1000 & $\infty$ \\
\hline 1 & & Model C $-\mathbf{1 5}$ & 15 \\
2 & 1.8 & 400 & 15 \\
3 & 2.0 & 667 & $\infty$ \\
\hline
\end{tabular}




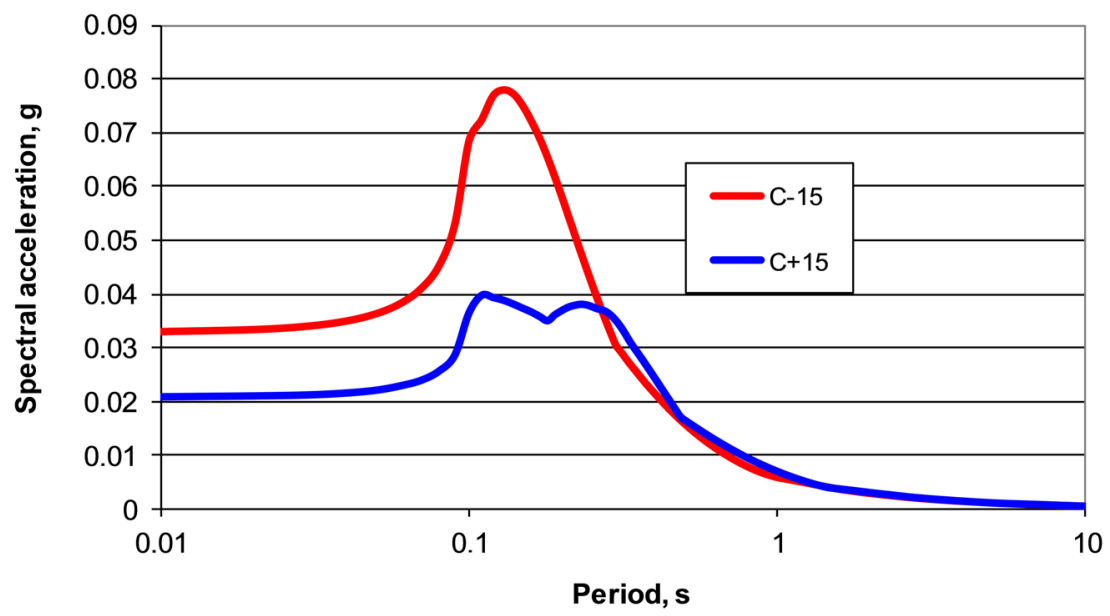

Figure 4. Response spectra of models $\mathrm{C}-15$ and $\mathrm{C}+15$.

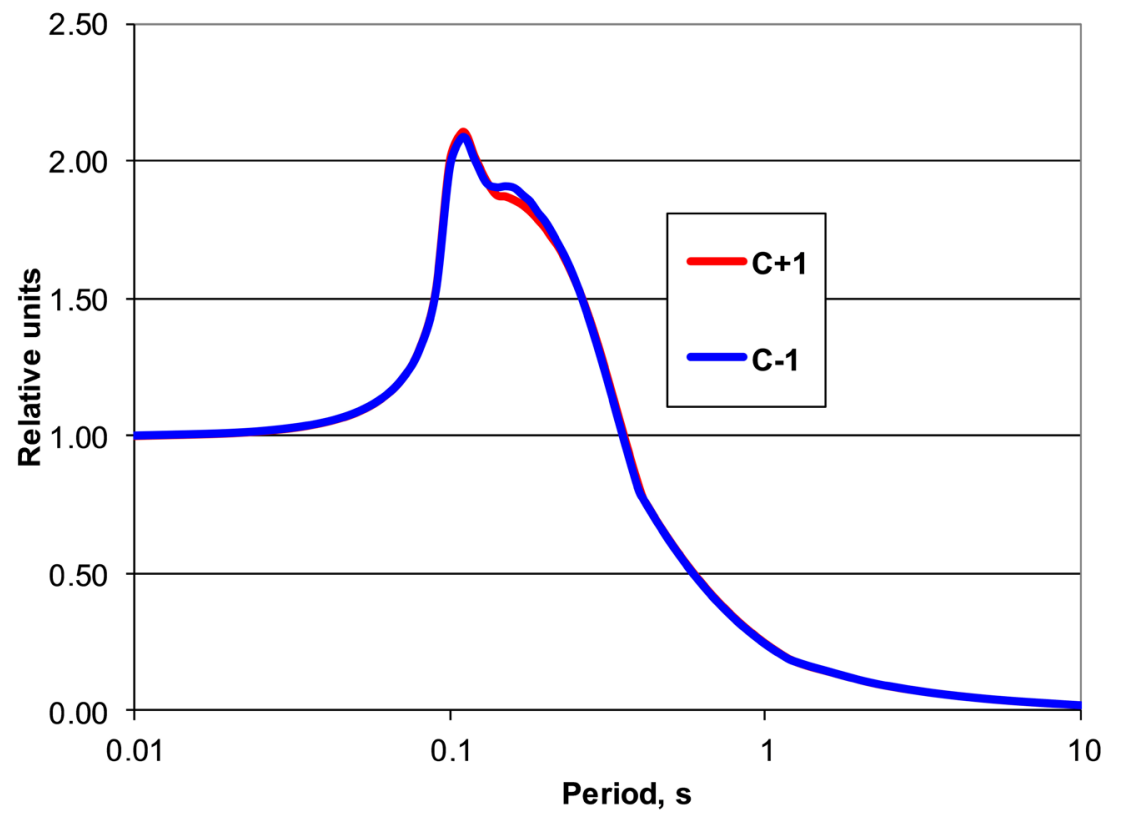

Figure 5. Comparison of dynamic coefficients of the "comb" model.

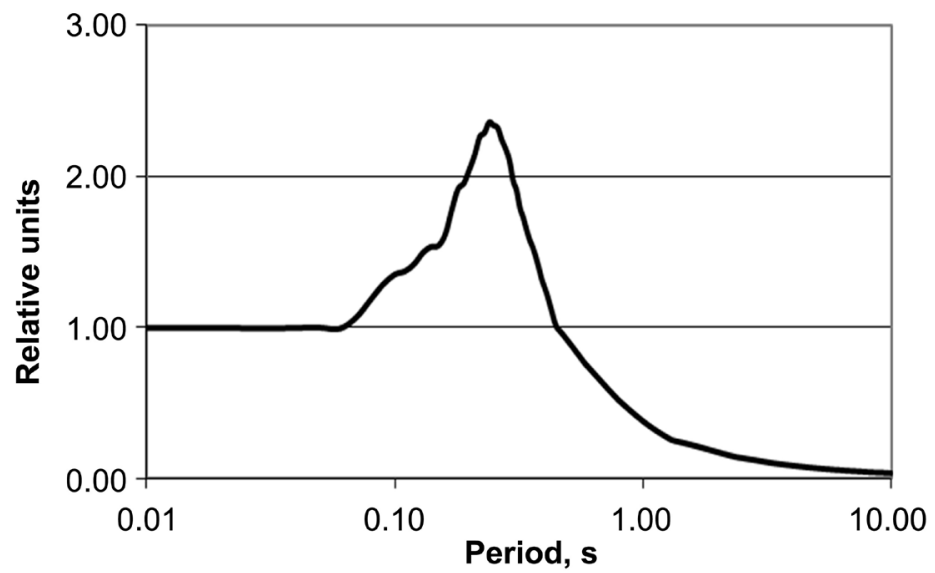

Figure 6. Graph of dynamic coefficient of average model. 
The average model corresponds to site class $C$ both in terms of the shear wave velocity and in terms of the soil coefficient $F_{a}$, which, according to [6], define as the ratio of the maxima of the dynamism coefficient of categories $\mathrm{C}$ and $\mathrm{B}$.

It cannot exclude that such a perfect coincidence of the dynamic coefficients for the "comb" models is a consequence of its ordering.

\subsection{On the Inpracticability of Using the Concept of Soil Classes}

The following example demonstrates the situation in the case of a "chaotic" or irregular model. Figure 7 shows the density and velocity sections of the soil model with an irregular structure and Figure 8 demonstrates a graph of the dynamic coefficient.
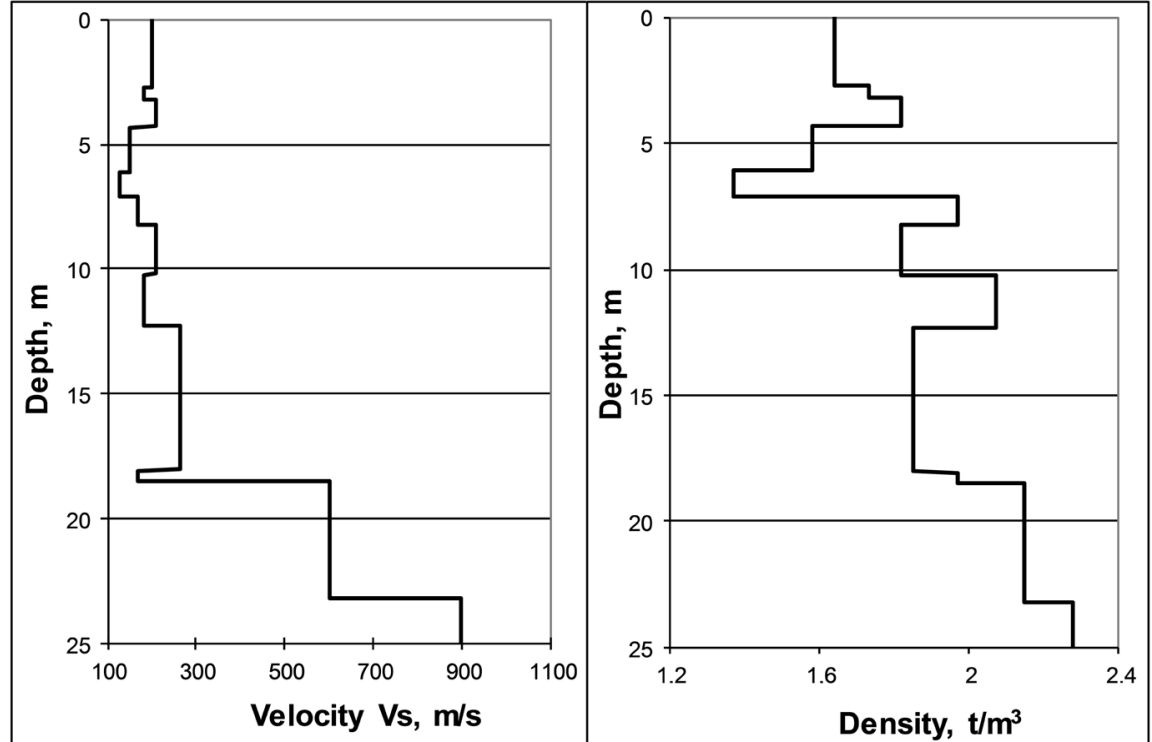

Figure 7. Parameters of irregular structure model.

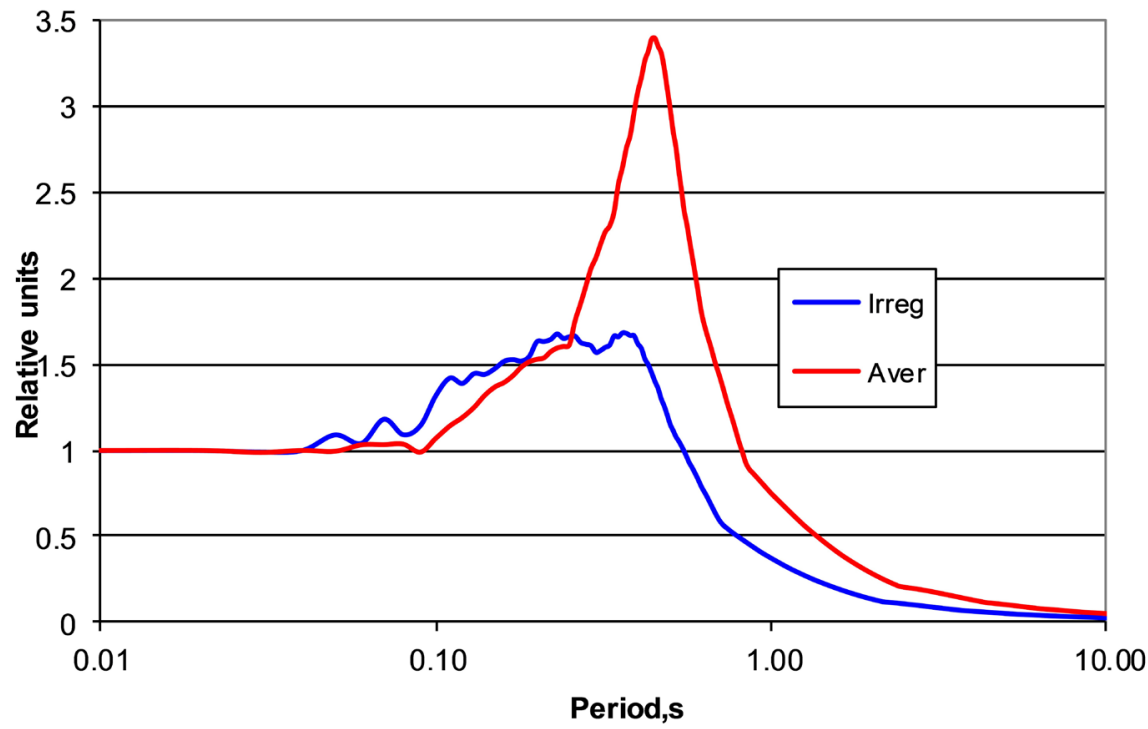

Figure 8. Dynamic coefficients of irregular and average models. 
In the density and velocity graphs, there are many areas with "anomalous" changes, i.e., where the model parameters-density and velocity-decrease relative to the "normal" law, which assumes an increase in both the density and velocity of elastic waves with depth, both due to an increase in geostatic pressure and local features of sedimentation. We also note that the relative changes in densities and velocities are small. Despite this, the influence on the parameters of seismic impacts, that reflected in the form of response spectra and dynamic coefficient, is very significant.

Let's compare the results of modeling an irregular model of the soil massif with the corresponding model, the upper part of which is represented by averaged parameters. The "chaotic comb" shown in Figure 7 is replaced by a homogeneous layer with the parameters $\rho=1.84 \mathrm{t} \cdot \mathrm{m}^{-2} \cdot \mathrm{c}^{-1}$ and $V_{s}=219 \mathrm{~m} / \mathrm{s}$. The resulting dynamic coefficients for these models shown in Figure 8.

The maximum dynamic coefficient of irregular model on Figure 8 does not exceed 1.6, which is less than for the model with no resonances. The maximum values of the dynamic coefficient are less than 1.9, which, according to Table 4, means the absence of resonant phenomena and, moreover, the manifestation of antiresonance effect. Discussion of this phenomenon is beyond the scope of this article.

The dynamic coefficient of the model with the averaged upper part of the soil massif is 3.4 and the site coefficient equal to the ratio $3.4 / 1.85=1.84$ corresponds to site class $\mathrm{D}$.

\subsection{The Role of Inverse Layers in the Soil Section}

Analysis of the materials of the study of the model with an irregular structure suggests a special role of the inverse layers in the soil section. The next series of model experiments aims to test this hypothesis. Examples taken from experimental data obtained at the seismic microzonation of Kaliningrad city. Here, in the floodplain of the Pregol River, rather thick layers of silt with low density and low values of the shear wave velocity found in the soil section. These features of the soil section have a noticeable effect on the seismic wave field [6]. To study the effect of the inverse layer on the spectral characteristics, two types of models used: normal with increasing density and velocity with depth, and anomalous with the presence of inverse layers in the section. The parameters of models shown in Table 6.

The modeling results presented in the form of dynamic coefficients in Figure 9. The maximum dynamic coefficient of the normal model is about 2.5 , and the abnormal model is less than 2. For the averaged model with $V_{\text {med }}=193 \mathrm{~m} / \mathrm{s} \rho_{\text {med }}$ $=1.76 \mathrm{t} / \mathrm{m}^{3}$, the dynamic coefficient shown in Figure 9 is 3.5, which corresponds to the site class D. At the same time, the shape of the graphs of the normal and averaged models differs sharply.

The averaged model characterized by a noticeable spectral peak at a period of about $0.7 \mathrm{~s}$, which roughly corresponds to the resonance of a loose layer on a 
Table 6. Parameters of normal, abnormal and average models.

\begin{tabular}{|c|c|c|c|}
\hline \multicolumn{4}{|c|}{ Normal model } \\
\hline № layer & Thickness of layer, $\mathrm{m}$ & Density, $t / \mathrm{m}^{3}$ & Velocity $V_{s}, \mathrm{~m} / \mathrm{s}$ \\
\hline 1 & 1.5 & 1.5 & 100 \\
\hline 2 & 7.5 & 1.7 & 240 \\
\hline 3 & 19 & 2.0 & 420 \\
\hline 4 & 2 & 2.1 & 470 \\
\hline 5 & $\infty$ & 2.5 & 800 \\
\hline \multicolumn{4}{|c|}{ Abnormal model } \\
\hline 1 & 6 & 1.8 & 230 \\
\hline 2 & 5 & 1.6 & 120 \\
\hline 3 & 5.5 & 1.7 & 200 \\
\hline 4 & 2 & 1.4 & 80 \\
\hline 5 & 11.5 & 2.0 & 320 \\
\hline 6 & $\infty$ & 2.5 & 800 \\
\hline \multicolumn{4}{|c|}{ Average model } \\
\hline 1 & 30 & 1.76 & 193 \\
\hline 2 & $\infty$ & 2.5 & 800 \\
\hline
\end{tabular}

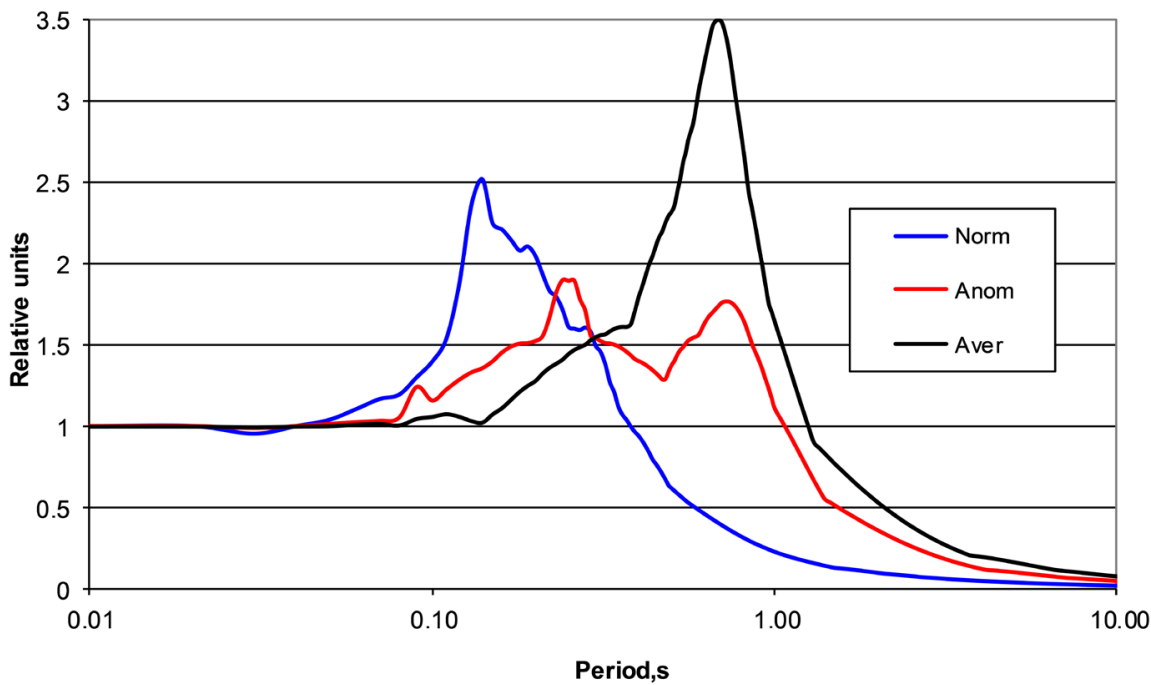

Figure 9. Dynamic coefficients of the normal, abnormal and average models.

hard half-space. At the same time, for a normal section, the maximum dynamic coefficient observed at a short period of 0.16 , due to the resonance on the upper layer with a power of $9 \mathrm{~m}$ and a speed of about $200 \mathrm{~m} / \mathrm{s}$. Thus, although the inverse layers make a significant contribution to the discrepancy between the soil properties of their classification using averaging, but the model of normal, i.e. monotonic increase in soil properties also does not correspond to the NEHRP classification. 


\subsection{Model Instead of Site Class}

So, it was shown above that both the NEHRP classification and in general the representation of the relationship of the site properties of the soil mass with the parameters of seismic impacts are unsatisfactorily described by the model with constant parameters. There is show that there is no need to use the concept of site classes.

We are deeply convinced that the concept of soil classes is rooted in macroseismic concepts previously used in the practice of engineering surveys. In this time, instead of instrumental parameters of seismic impacts for evaluation of seismic impacts, macroseismic intensity used. The definition of intensity is essentially discrete; it is based on a macroseismic assessment of seismic impacts in grads of a macroseismic scale. The discrete intensity had to be brought into line with the discrete representation of soil conditions, which was implemented in the form of site classes. This discreteness was violated by the formula of the seismic rigidity method, by which the seismic intensity could be calculated with any accuracy, essentially a continuous quantity. This made it necessary to match the continuity of seismic impacts with the continuity of the representation of the soil conditions.

Instead of soil classes, the main concept of seismic microzonation, that determines the features of engineering and seismological surveys in the studied territory, it proposed to use the concept of model of seismic ground conditions. This concept includes all local features of the geological situation that determine the specifics of seismic impacts-their amplitude and spectral composition.

At the same time, concrete examples showed how to link the properties of soils with the parameters of seismic impacts without using the concept of soil classes. The question is how the soil model form. In the model examples given in this article, the models formed artificially in order to test a particular hypothesis. In concrete examples from the practice of seismic microzonation, the soil model should be formed based on engineering-geological and geophysical, mainly seismic prospecting, data. For engineering surveys over sufficiently large areas, it is advisable to generalize these data in the form of several representative models of soil conditions. For concentrated objects, one model is sufficient. For each model, the parameters of seismic impacts are determined according to the standard method described above, which uses pulsed excitation of vibrations in the medium model. Each model corresponds to its own individual parameters of seismic impacts in the form of response spectra, dynamic coefficients or calculated accelerograms.

The relationship between the soil properties of the foundations of structures and the parameters of seismic impacts on them using model representations described in the book [10] and partially recorded in the latest seismic standards of Russia [9].

\section{Conclusions}

Thus, the above model calculations show a complete failure of the classification 
of soils according to the recommendations of the NEHRP. Special attention is paid to the disadvantages of using the averaged model of soil properties, which is one of the most important features of the classification under consideration. At the same time, a number of examples given substantiate the statement about the uselessness of using the concept of soil classes in general.

Instead of soil classes, the basic concepts of seismic microzonation that determine the features of engineering and seismological surveys in the studied area, it is proposed to use the concept of a model of seismic ground conditions that takes into account all the heterogeneities of the soil massif. A method is proposed to determine the parameters of seismic impacts that most adequately correspond to the specific ground conditions of the construction site.

\section{Conflicts of Interest}

The author declares no conflicts of interest regarding the publication of this paper.

\section{References}

[1] Building Seismic Safety Council (1997) National Earthquake Hazard Reduction Program (NEHRP) Recommended Provisions for Seismic Regulations for New Buildings and Other Structures. Part 1: Provisions (FEMA 302). Building Seismic Safety Council, Washington DC.

[2] European Committee for Standardization (2003) Eurocode 8: Design of Structures for Earthquake Resistance-Part 1: General Rules, Seismic Actions, and Rules for Buildings. Brussels, 229 p.

[3] Dobry, R., Borcherdt, R., Crouse, C.B., Idriss, L.M., Joyner, W.B., Martin, G.R., Power, M.S., Rinne, E.E. and Seed, R.B. (2000) New Site Coefficients and Site Classification System Used in Recent Building Seismic Code Provisions. Earthquake Engineering, 16, 41-67. https://doi.org/10.1193/1.1586082

[4] Klimis, N.S., Margaris, B.N. and Koliopoulos, P.K. (1999) Site-Dependent Amplification Functions and Response Spectra in Greece. Journal of Earthquake Engineer ing, 3, 237-270. https://doi.org/10.1080/13632469909350346

[5] Barani, A., De Ferrari, R., Ferretti, G. and Eva, C. (2008) Assessing the Effectiveness of Soil Parameters for Ground Response Characterization and Soil Classification. Earthquake Spectra, 24, 565-597. https://doi.org/10.1193/1.2946440

[6] Gallipoli, M. and Mucciarelli, M. (2009) Comparison of Site Classification from $V_{s 30}, V_{s<i o}$ and HVSR in Italy. Bulletin of the Seismological Society of America, 99, 340-351. https://doi.org/10.1785/0120080083

[7] Zaslavsky, Y., Shapira, A., Goldstein, M., et al. (2012) Questioning the Applicability of Soil Amplification Factors as Defined by NEHRP (USA) in the Israel Building Standards. Natural Science, 4, 631-639. https://doi.org/10.4236/ns.2012.428083

[8] Anbazhagan, P., Sheikh, M.N. and Parihar, A. (2013) Influence of Rock Depth on Seismic Site Classification for Shallow Bedrock Regions. Natural Hazards Review, 14, 108-121. https://doi.org/10.1061/(ASCE)NH.1527-6996.0000088

[9] SP 283.1325800.2016 (2016) High Critical Building Objects. Rules of Seismic Microzonation. (In Russian)

[10] Aleshin, A.S. (2017) The Continuum Theory of Seismic Microzonation. 300 p. (In 
Russian)

[11] Bardet, J.P., Tobita, T. and Nera, F. (2001) Computer Program for Nonlinear Earthquake Site Response Analyses of Layered Soil Deposits. University of Southern California, 44

[12] Kharkevich, A.A. (1957) Theoretical Bases Radio. 348 p. (In Russian)

[13] SP 14.13330.2014 (2014) Construction in Seismic Areas. (In Russian) 